\title{
Violencia política y memoria restaurativa en Redoble por Rancas, de Manuel Scorza*
}

\section{POLITICAL VIOLENCE AND RESTORATIVE MEMORY IN REDOBLE POR RANCAS, BY MANUEL SCORZA}

Amal Ait Nani

Universidad Hassan II, Marruecos

profeamalya@gmail.com

\section{RESUMEN}

En la década de 1970, Manuel Scorza publicó su primera novela, Redoble por Rancas, obra finalista del Premio Planeta 1969 y que forma parte del ciclo llamado $L a$ guerra silenciosa. Su enorme éxito internacional contribuyó a visibilizar el contexto trágico y violento de la sociedad andina del centro del Perú de mediados del siglo Xx. Dentro de este marco, nuestra propuesta de análisis está orientada a explicar cómo se ejerce la imaginación en la mencionada novela cuando intenta representar la violencia política en sus múltiples dimensiones. Asimismo, buscamos comprobar cómo la ficción en Redoble por Rancas consigue proporcionar nociones acerca de la memoria colectiva, en la medida en que visibiliza las historias no contadas y silenciadas, y desde luego pone el dolor de las víctimas en la escena pública como un acto de justicia poética. Para ello, las nociones de memoria restaurativa (Vivanco, 2018) y justicia poética (Nussbaum, 1997) establecen las bases teóricas que apoyan nuestra indagación.

\section{ABSTRACT}

In the 1970s, Manuel Scorza published his first novel, Redoble por Rancas. A finalist of the 1969 Planet Prize, this novel belongs to the cycle of La guerra silenciosa. Its enormous international success contributed to revealing the tragic and violent context of the Andean society of Central Peru in the mid-twentieth century. Within this context, our analysis aims at explaining how fiction is used in this novel to represent reality and denounce political violence. It also seeks to verify how fiction in Redoble por Rancas can provide notions about collective memory revealing the untold and silenced stories while offering itself as an instance for restorative justice. To this end, the notions "Restorative Memory" (Vivanco, 2018) and Poetic Justice (Nussbaum, 1997) are going to establish the theoretical bases that support our inquiry.

KEYWORDS: Redoble por Rancas, political violence, social denunciation, restorative memory

PALABRAS CLAVE: Redoble por Rancas, violencia

política, denuncia social, memoria restaurativa

\footnotetext{
* Este ensayo forma parte de mi actual proyecto de tesis de doctorado sobre la función ética de la ficción en la narrativa de Manuel Scorza.
} 


\section{INTRODUCCIÓN}

En la década de los sesenta emergieron en el panorama literario latinoamericano escritores que, agrupados en el denominado fenómeno del boom, rompieron la rigidez de la narración sustentada en el canónico indigenismo ortodoxo de la primera mitad del siglo $x x$. De igual manera, aportaron una escritura experimental, partidaria de la inserción de nuevas técnicas formales, con diversos modelos de expresión.

En términos estéticos y literarios, Manuel Scorza' fue uno de los integrantes peculiares del boom², pues su obra narrativa fue marcada por una renovación estética que incorpora tres grandes discursos literarios: el fenómeno del boom, el neoindigenismo y el testimonio. Igualmente, las intersecciones dentro de su escritura dieron paso a la convergencia entre hechos reales y fantásticos y, desde luego, consiguió forjar una nueva narrativa de tono social.

Habría que añadir que muchos estudios sobre la narrativa de Manuel Scorza han afirmado que una de las bases clave para el proceso de renovación en su obra literaria fue el periodo histórico del continente, definido por convulsiones sociopolíticas resultantes de sucesivos golpes de Estado en varios países latinoamericanos.

En relación con el contexto peruano, la violencia prevaleció durante mucho tiempo. Como consecuencia de las estructuras anacrónicas del modelo feudal, se produjo un estancamiento social y económico que se incrementó a comienzos de la década de 1960. En consecuencia, se intensificaron las protestas de las comunidades indígenas en la sierra, con el objetivo de restaurar sus tierras usurpadas por los latifundios. Sin embargo, sus demandas se enfrentaron a una actitud represora del gobierno y, desde luego, culminaron en una sangrienta rebelión "solitaria".

1 Manuel Scorza (1928-1983) fue un novelista y poeta peruano de la generación del 50. Junto a otros escritores contribuyó al neoindigenismo peruano. Por su actividad política, tuvo que exiliarse dos veces. En su producción poética encontramos Las imprecaciones (México, 1955), poemario con el que obtuvo el Premio Nacional de Poesía de 1956; Los adioses (1960); Desengaños del mago (1961); Réquiem por un gentilhombre (1962); Cantar de Túpac Amaru (1969); El vals de los reptiles (1970), y Poesía incompleta (1976). Scorza escribió un ciclo novelístico bautizado La guerra silenciosa, compuesto por Redoble por Rancas (1970), Historia de Garabombo, el invisible (1972), El jinete insomne (1977), Cantar de Agapito Robles (1977) y La tumba del relámpago (1979). Finalmente, La danza inmóvil (1983) constituye el proyecto que no fue culminado debido a la muerte del escritor en un accidente de avión (vuelo París-Bogotá) en el año 1983.

2 Aquí subrayamos que en este exitoso boom de la literatura se sitúan escritores que, a pesar de conseguir difusión mundial - como es el caso de Manuel Scorza-, fueron excluidos inexplicablemente del resto de los autores del mencionado fenómeno. Al respecto, Schwartz (2009) menciona: "A finales de los años cincuenta, Scorza empezó su propia empresa editorial llamada Populibros, que produjo ediciones masivas, económicas, de novelas que se vendían en las ferias literarias callejeras. El proyecto de Scorza casi coincidió históricamente con el boom internacional, y lo contesta en un esfuerzo anticomercial que puso a disposición de los lectores locales ediciones accesibles". 
Sin duda, si ubicamos los hechos relatados y la evolución literaria en este marco político, encontramos suficientes motivos por los cuales los escritores peruanos forman parte de estos vaivenes de la coyuntura social. En concreto, muchos han encontrado en la poesía y la novela un terreno elegante y con estilo para expresar su protesta que indudablemente no era muy bien recibida por los políticos que gobernaban. De hecho, muchos escritores y poetas eran desterrados o encarcelados. Entre ellos, Manuel Scorza, quien fue exiliado dos veces por su filiación con el Movimiento Comunal del Perú y por su colaboración en las rebeliones de Cerro de Pasco. Estas últimas terminaron en una masacre que no tuvo eco en las fuentes oficiales. Años después, Scorza regresa en secreto a la región y durante dos años reúne información de los sobrevivientes, hace grabaciones, fotografías y recopila apuntes para luego convertir en ficción las sangrientas batallas, a las que había asistido personalmente.

De hecho, en la década de 1970, Manuel Scorza escribió cinco novelas que componen la pentalogía de La guerra silenciosa. El enorme éxito internacional que tuvo fue gracias a la publicación de la primera novela del mencionado ciclo, Redoble por Rancas (1970) ${ }^{3}$. Esta novela recompone la historia de una "lucha solitaria" en el Perú en las décadas de 1950 y 1960, cuando los campesinos indígenas de los Andes centrales se enfrentaron desarmados a los terratenientes y a la empresa minera norteamericana Cerro de Pasco Corporation. El motivo de esta confrontación fue la apropiación progresiva de la tierra por parte de esta empresa, y culminó en una masacre de la comunidad de Rancas a mediados de los sesenta. De hecho, el peculiar contrapunto que establece la diégesis de la saga con la historia ha permitido que se inscriba como un testimonio del contexto trágico y violento de la sociedad andina del centro del Perú de mediados del siglo xx. De igual manera, a nuestro juicio, su estatus de narrativa de memoria le ha propiciado un potente vigor como para intervenir en el futuro sociopolítico del Perú.

Dentro de este marco, nuestra propuesta de análisis, por un lado, está orientada a explicar cómo se ejerce la imaginación en la novela $\mathrm{RpR}^{4}$ cuando intenta representar la realidad de los años sesenta, marcada por el desconocimiento de la dignidad humana de los comuneros, la exclusión social, la asimetría del poder del Estado y la violencia física. Por otro lado, desde el análisis literario y el uso de herramientas de otras disciplinas, nuestra tarea busca desenredar los propósitos éticos de esa ficción. Como seguimiento, nuestro análisis contará con dos apartados: en el primero, analizaremos cómo se retrata la violencia política con sus múltiples dimensiones en la mencionada novela. En el segundo, planteamos la narrativa del corpus como una alternativa para implementar la justicia y la reparación, en la medida en que contribuye a visibilizar las historias silenciadas y

3 En el presente trabajo manejamos la edición publicada en 1983 por la editorial Plaza y Janés, Barcelona.

4 Se usará la abreviatura RpR para aludir a la obra del corpus objeto de estudio, Redoble por Rancas. 
desde luego pone el dolor de las víctimas en la escena pública como un acto de justicia poética. Para ello, las nociones de memoria restaurativa (Vivanco, 2018) y justicia poética (Nussbaum, 1997) establecen las bases teóricas que apoyan nuestra indagación.

\section{VIOLENCIA POLÍTICA Y SU CONFIGURACIÓN DISCURSIVA EN REDOBLE POR RANCAS}

En el Perú, el entendimiento académico y popular sobre la violencia política muestra una marcada asincronía histórica. En otras palabras, la historia nacional peruana define la época de la violencia como un periodo histórico que se inició en la década de 1980 , refiriéndose al enfrentamiento entre Sendero Luminoso (SL) y las fuerzas del Estado (1980-2000). Pero este postulado, según Chati (2015), surge como resultado de debates oficiales, académicos y populares que accedieron a reducir la amplia esfera de violencia en el país. Asimismo, el autor añade que para miles de campesinos, donde no hubo batalla entre SL, las Fuerzas Armadas y la población, hubo violencia política, social y económica (pp. 51-52). De igual manera, Cortez (2020) ratifica que el tema de la violencia política no se puede reducir a la década de 1980. Al contrario, "según su orden cronológico, la violencia política ya apareció en la primera novela peruana, El padre Horán, en 1948". El mismo investigador agrega que, incluso, el tratamiento retórico de la violencia se remonta al libro fundacional del Perú, Comentarios reales de los incas (1609), donde el Inca Garcilaso da cuenta de la destrucción del país y de la sociedad andina por la brutal guerra civil entre invasores y conquistadores españoles. De hecho, si las obras del Inca Garcilaso constituyen la base de la creación literaria peruana, podemos constatar que, décadas después, muchos autores como César Vallejo, José María Arguedas, Mario Vargas Llosa y Manuel Scorza han abordado en sus narrativas las múltiples violencias políticas que constituyen toda la historia del Perú contemporáneo.

En el mismo marco, si comparamos la representación retórica de la violencia política con la historia oficial, encontramos que en esta última "hay una sincronía de sufrimiento". (Chati, 2015, p. 52). Al respecto, resaltamos el caso de las sublevaciones campesinas de las zonas altoandinas de Cerro de Pasco (de 1960 a 1962) en reclamación de sus tierras arrebatadas injustamente. Estos levantamientos culminaron con un enfrentamiento entre campesinos indefensos y las Fuerzas Armadas. Como consecuencia del incidente, hubo muchos muertos y heridos. Sin embargo, es preciso señalar que a estas víctimas en la historia oficial se les ha privado de justicia restaurativa, ya que fueron reconocidas como "comunidad subversiva"5. Más aún, este hecho no tuvo eco en la prensa de aquel entonces, hasta pasados diez años después de esta masacre, cuando César Hildebrandt publicó un informe sobre esta en la revista Caretas:

5 El énfasis es nuestro. 
En marzo de 1962, aproximadamente treinta comuneros en busca de tierra fueron masacrados por fuerzas policiales. [Sin embargo,] "Sorda tensión crece en Pasco" era el titular de Expreso el 3 de marzo. El 5 de marzo, La Prensa abría su edición así: "Mueren ocho comuneros al desalojar fundos en Cerro de Pasco". Pero al día siguiente su corresponsal rectificaba: "Operación Desalojo de Fundos de Pasco ha dejado 15 muertos". La versión definitiva de La Prensa sería dada el 7 de marzo: "Ocho muertos sería el total en desalojo". (Hildebrandt, como se citó en Huamanchumo, 2013, p. 253)

En este orden de ideas, tras muchas indagaciones, podemos afirmar que el primer registro escrito sobre estas masacres sigue siendo la pentalogía de Manuel Scorza. A este respecto, conviene mencionar que el propio autor escribió sobre el conflicto recurriendo a otras modalidades discursivas no ficcionales. En este caso, nos referimos a la narración oral, la declaración testimonial de víctimas o del propio Scorza, que había experimentado lo que registró en la ficción. Dicho de otro modo, Scorza se propone como testigo que hace uso del elemento "no ficcional" para dar voz a las víctimas. Sin embargo, todo es parte de la ficción, pero al mismo tiempo su contextualización histórica con datos precisos y la veracidad de la masacre dejan al lector perplejo sobre si es historia o ficción lo que se está narrando. En todo caso, subrayamos que con las referencias reales ${ }^{6}$ citadas en RpR el narrador reafirma su compromiso de no inventar, lo cual dota al relato de "efecto de realidad". No obstante, es preciso señalar que, en la mencionada novela, no se trata de una ficción que sirve al testimonio, sino de una ficcionalización del testimonio.

Ahora bien, partiendo de los supuestos anteriores, consideramos que Scorza mediante la verosimilitud alcanza a elaborar una novela poblada de significaciones ideológicas, ya que tanto la forma como el fondo expresan una denuncia de los abusos y de la corrupción de instituciones gubernamentales y judiciales, entre otros.

Por lo tanto, mientras avanzamos en la lectura de la novela objeto de estudio, podemos constatar que el autor mediante descripciones simbólicas e hiperbólicas metaforiza las injusticias cometidas como violencia persistente, ya sea en su aspecto simbólico o material. En tal sentido, subrayamos que esta novela se instaura como un catalizador del conflicto de la época. Desde esta perspectiva, el presente apartado pretende analizar cómo RpR representa la violencia política y cómo da cuenta del tránsito de esta a otras formas de violencia, provocadas por las injusticias y la polarización de las clases sociales.

6 Los nombres de lugares, personas e instituciones, tales como Rancas, la plaza de Yanahuanca, el cementerio de Chinche, Héctor Chacón, la Guardia Civil, el juez Montenegro y la Cerro de Pasco Corporation, son referencias reales que Scorza incluye en el discurso ficticio de RpR. En vista de ello, el autor confirma su estatuto de narrador y testigo de una memoria transmitida a través de su propio testimonio y otros testimonios orales que ha recopilado. 
Si bien existen múltiples y variados intentos de definición del concepto polisémico de violencia, el campo semántico de violencia política aparece más definido. Se trata, más bien, de actos violentos llevados al cabo por grupos organizados para cambiar la estructura del poder o su distribución. Por lo tanto, a menudo el concepto aparece vinculado al ámbito político. Al respecto, Foucault (2006) analiza la violencia de acuerdo con la conceptualización del poder y los dispositivos de soberanía, entre otros, y afirma que la violencia es omnipresente en todas las relaciones de poder. Arendt (2005), por otro lado, considera que la violencia no es forzosamente inherente al poder y explica que se presenta como el último modo de acción política.

En el mismo marco, mencionamos otro postulado teórico que plantea el complejo fenómeno de la violencia desde una visión integral del conflicto. Se trata del triángulo de violencia de Galtung (1990). Según el estudioso, la violencia se categoriza en tres tipos: violencia estructural, violencia cultural y violencia directa. La que encarna el tipo visible es la violencia directa. Para Galtung (1990), estas tres categorías se manifiestan de la siguiente manera: la violencia directa implica destrucción física o muerte; la violencia social es implícita y ocurre cuando se utilizan las diferencias de tipo religioso-étnico para legitimarla; mientras que la violencia estructural puede manifestarse por medio de la marginación y la exclusión, ya que los marcos políticos y sociales establecen una determinada coyuntura para mantener un régimen de beneficios para ciertos grupos y marginar a otros. A grandes rasgos, la violencia cultural contribuye a naturalizar la violencia estructural y ambas se revelan a través de la violencia directa.

Partiendo de estos supuestos teóricos, señalamos que los rastros de violencia, en el aspecto textual de RpR, se manifiestan de diversas formas, y se podrían localizar dentro de los dos tipos de violencia, tanto visible como invisible. No obstante, dentro de estas categorías, la violencia que subyace en el relato es la que no se puede percibir explícitamente, sino que se realiza a través de complejos procesos que están incrustados en la vida social del campesino y que facilitan la reproducción sistemática de otra serie de violaciones. En este orden, nuestro enfoque pretende analizar cómo la violencia invisible se evidencia por medio de la violencia directa y cómo transforma el mundo social de los campesinos de Rancas en un escenario complejo y lleno de abusos. Y, en última instancia, cómo la violencia visible condena a las víctimas a un estado de subalternidad. Estas premisas se desarrollarán en lo que sigue.

\section{La violencia directa y visible en Redoble por Rancas}

Desde el primer capítulo de RpR, “Donde el zahorí lector oirá hablar de cierta celebérrima moneda" (Scorza, 1983, p. 13), el narrador trama el contexto y el espacio atravesado por la represión. En concreto, la representación de la amenaza de violencia aparece, irónicamente, cuando nadie se atrevió a tocar la moneda de bronce de un sol (moneda peruana) 
que se le cayó al doctor Montenegro, juez de primera instancia, mientras cruzaba la plaza Yanahuanca. A partir de este momento, se gestan implacables figuraciones textuales de las violaciones de derecho y las prácticas de negación de la dignidad del "otro", tal como se percibe en este fragmento:

"iEs el sol del doctor!", susurraban exaltados. Al día siguiente, temprano, los comerciantes de la plaza la desgastaron con temerosas miradas. "iEs el sol del doctor!", se conmovían. Gravemente instruidos por el director de la Escuela - "No vaya a ser que una imprudencia conduzca a vuestros padres a la cárcel"-, los escolares la admiraron al mediodía: la moneda tomaba sol sobre las mismas desteñidas hojas de eucalipto. Hacia las cuatro, un rapaz de ocho años se atrevió a arañarla con un palito: en esa frontera se detuvo el coraje de la provincia. (Scorza, 1983, p. 14)

Como observamos, el ejercicio de la violencia presupone una situación de asimetría, en la que la víctima se dispone como un no-sujeto, desprotegido e indefenso; lo que incrementa el circuito de la violencia. Asimismo, resaltamos que la violencia no se limita a lo extremo y visible, sino que atraviesa diferentes hábitos y prácticas sociales que comprenden pensar en los demás de forma deshumanizada, desestimando su valor, es decir, su capacidad de actuar contra las injusticias.

Así, observamos que discurso, poder y violencia se vinculan en una estrecha relación. Es decir, quien domina el discurso es quien controla la situación y le corresponde usar la violencia. El discurso, por tanto, se implementa como un poderoso medio de presión que podría conducir a actos de violencia. De acuerdo con Cantis Carlino (2000), el sujeto violento es una persona que se maneja con convicciones autoritarias, excluyentes y un lenguaje de acción que cercena a otro, y también a su propio yo o al grupo al que pertenece, la posibilidad de cuestionarse y pensar (p. 336). De hecho, en RpR las situaciones que retratan la relación asimétrica entre los campesinos, las autoridades y los hombres del poder hegemónico revelan un alto grado de degradación humana del victimario, como lo hace notar el narrador en este pasaje:

Es necesario - dijo el juez Montenegro abriendo apenas los labios, manchados por la mala educación del durazno jugoso- que esos piojosos aprendan, de una vez. Esos yanacochanos solo entienden los golpes. - La voz se endureció-. Hoy tropezarán con Montenegro. Hace tiempo que se sufren robos de ganado por estas alturas. Las autoridades de Yanacocha son los abigeos. Hoy entrarán en la cárcel o no me llamo Montenegro. (Scorza, 1983, p. 157)

De este ejemplo destacamos que, sistemáticamente, el victimario busca anular a la víctima despojándola de su condición de sujeto o de su pertenencia igualitaria al grupo humano. Y cuando esto ocurre aparece la humillación. Para ilustrarlo, especificamos otro caso: cuando Héctor Chacón se dirigió al juez Montenegro y a la mujer de este para reclamar los daños que han causado a su caballo, fue recibido con gran desprecio y hostilidad, tal como vemos aquí: 
El doctor arrugó el entrecejo.

- ¿Quién es Lunanco?

-Un mi caballo retenido en tu pesebre.

-Habrá hecho daño.

-No es tu pasto, doctor. Es mi propio pasto.

El juez me miró con los ojos atravesados.

-Yo no sé nada. Lo único que sé es que ustedes abusan de mis pastos.

-Pero, doctor...

El juez se paró.

— ¡Nada, no quiero saber nada! ¡Lárgate de aquí, cholo de mierda! (Scorza, 1983, p. 127)

Tal como se puede inferir, la segregación o la negación de los derechos del sujeto víctima del abuso se opera por medio de la degradación de su condición de ser humano. Entonces, la humillación se produce como mecanismo excluyente que se gesta en el mundo social de los personajes campesinos y que incluso accede a legitimar prácticas de injusticia. Esta perspectiva también se evidencia en varias situaciones de la trama, donde el personaje de Fortunato expresa su desconfianza en las instituciones y en las leyes, ya que estas resultan ser deficientes para asegurar y mantener los derechos de quienes son rechazados socialmente. Ahora bien, para reaccionar ante la experiencia de tormento, a menudo en los personajes víctimas de los abusos de poder se manifiestan sentimientos en formas de dolor, desesperación e impotencia, como se puede notar en este ejemplo:

Eran las doce. Empleados y obreros mal vestidos se alineaban en las veredas. El viejo convocaba las furias de su impotencia.

— ¡Han cercado Rancas! ¡Han cercado Villa de Pasco! ¡Han cercado Yanacancha! ¡Han cercado Yarusyacán! ¡Encerrarán el cielo y la tierra! ¡No habrá agua para beber ni cielo para mirar! (Scorza, 1983, p. 149)

De hecho, se establece una estrecha relación entre humillación y otras emociones morales como la indignación, la rabia, el odio y la ira. Esta carga de sentimientos tiene que ver con la pérdida de dignidad, la lesión de la identidad y la experiencia de rechazo de la comunidad social y política. En este sentido, el resentimiento y la ira generados por la humillación posibilitan el desencadenamiento de la violencia o la agresión. A este respecto, mencionamos lo que dice Sofsky (2006) sobre las lesiones de la violencia: lo que realmente rompe al hombre no es la herida que desfigura el cuerpo, sino su posición en el mundo que queda completamente alterada. Y añade que cuando se sufre violencia, se siente impotente. La violencia afecta al hombre de la manera más íntima, subyugándolo en su totalidad (p. 60). 
En este orden de ideas, constatamos que la humillación, a lo largo de la novela que se analiza aquí, resulta ser una de las estrategias de la violencia visible. Puede ser examinada como una práctica sistemática y como un aparato de control social, e incluso como una herramienta que puede activar la violencia propiamente dicha. Es por esta vía que los hombres de autoridad se vinculan con la barbarie y la brutalidad, toda vez que sus actos se perfilan como una actividad destructiva y deliberada que desprecia los derechos de los comuneros; estos, como víctimas de los abusos del sistema, se encuentran en una condición de vulnerabilidad y están reiteradamente expuestos a la humillación que les resta sus derechos y su capacidad de reacción ante el mal recibido. De hecho, la humillación produce una grieta y marginalización en el mundo social de los campesinos protagonistas de RpR.

Por otro lado, si volvemos la mirada a la construcción discursiva de la humillación como estrategia de crueldad y violencia, observamos que el narrador en RpR confiere al discurso una especie de brutalidad y dureza que, en cierto modo, formaliza la violencia enunciativa. En otras palabras, el narrador recrea el lenguaje oral con sus diversas particularidades socioculturales de diferentes estratos. Sin embargo, la violencia en el lenguaje exige entenderse no solamente como estrategia literaria, sino como una forma de connotar el malestar social. Dicho así, constatamos que la violencia enunciativa, cuando es manejada por el agresor, se manifiesta principalmente en forma de amenazas e insultos que socavan la moral y la ética. Esta violencia verbal se establece en el discurso por medio de diferentes campos semánticos de insultos entre los que podemos distinguir cinco campos: (1) el campo "animal" (carbón, perro, piojoso); (2) el campo de "partes del cuerpo y sexualidad": (lameculos, hijo de puta, cojones); (3) el campo "racista" (salvajes); (4) el campo "escatológico" (comemierda, mierda, cholo de mierda); y (5) el campo referente al "retraso mental" (cojudo, imbécil). Del mismo modo, la violencia verbal es recíproca cuando se trata de los campesinos víctimas de la violencia extrema. Estos, de igual manera, usan un denso vocabulario de violencia que a menudo tiende a animalizar (perros, la bestia) al victimario o cosificarlo (los enchaquetados, el traje negro). Como podemos observar, los mecanismos enunciativos de la violencia verbal en RpR configuran, en el primer caso, una serie de imágenes que atribuyen al subalterno, víctima del acto violento, etiquetas degradantes que se perfilan en adjetivos; en su mayoría minimizan a las personas en cuestión, como una estrategia de humillación y anulación. En el segundo caso, cuando se pretende describir al victimario en palabras de las víctimas, se le asignan otras etiquetas que lo identifican con la bestia y el animal. Este posee la fuerza y la autoridad para someter al "otro negado" a una serie de abusos e injusticias.

No obstante, notamos que cuando el conflicto entre los personajes campesinos y los de autoridad u hombres de la ley no encuentra mecanismos para su resolución, los actores involucrados no se limitan a los mecanismos insertos en las prácticas sociales, sino que recurren directamente a la violencia física, como lo hace notar Galtung (1998) 
cuando menciona que los conflictos son originados por la diferencia de intereses entre los sujetos y que, por tanto, la violencia es la anulación de toda comunicación y demuestra el fracaso de la gestión de un conflicto (p. 14). De esta manera, los personajes campesinos, empujados a la autodefensa, se posicionan en la acción recurriendo a la lucha y protestando contra el ataque a su propiedad. Por lo tanto, el enfrentamiento adquiere la apariencia de un destino imperativo, como lo subrayan Fortunato y Héctor Chacón, cuando conciben la lucha contra el adversario como una cuestión de honor, en cuanto involucra el futuro de la comunidad.

En este orden de ideas, la masacre a la que se expusieron los comuneros, tal como lo describe el desenlace de la novela, es la instrumentalización del salvajismo en su estado más puro. Por eso, no en vano se nombra en el corpus a los hombres del poder hegemónico y a los de la ley como animales, ya que la deshumanización del victimario plantea su metamorfosis en una bestia al perder toda inhibición humana para la brutalidad. En tal sentido, constatamos que la violencia libera a quien la comete y destruye a quien la padece, como lo expresa Sofsky (2006). A medida que el primero se expande, el segundo se contrae hasta la nulidad; e incluso si la víctima de la violencia sobrevive, nunca volverá a ser quien era antes (p. 60).

Al respecto, subrayamos la importancia del cuerpo como materialidad de la violencia. De acuerdo con Sofsky (2006), una vez cometido un acto de violencia, ya no es la violencia en sí lo que se percibe, sino las marcas que esta violencia ha dejado en el cuerpo. En este sentido, el cuerpo se presenta como huella y soporte material de la violencia. Estas huellas permiten la operación de transmitir el recuerdo de la violencia. Esta premisa se evidencia en el último capítulo de RpR, cuando Scorza hace hablar a los muertos, víctimas de la masacre, a través de su destrucción:

-Así es, fracasaron: las piedras no rodaban. Los guardias los corrieron a balazos. Allí cayó el muchachito Maximino.

- ¿El que construyó el espantapájaros?

-Así es, señor Personero. Vi caer al muchachito y sentí una quemazón en la sangre, saqué mi honda y le solté una pedrada en la cara a uno de los guardias. Me disparó su metralleta. Caí de espaldas con la barriga abierta. (Scorza, 1983, p. 253)

Como vemos, la inscripción de huellas corporales en el texto desafía la sensibilidad del lector para que pueda imaginar el grado de sufrimiento que siente la víctima. De este modo, el cuerpo, en un escenario de salvajismo, se convierte en un símbolo que se forja socialmente en una nueva red de sentido. En otras palabras, el cuerpo se muestra como el emisor de signos de la crueldad y la vileza como prácticas de brutalidad extrema a las que están sometidos los personajes campesinos como sujetos no históricos y despojados de todo derecho de defensa. 


\section{La violencia estructural o invisible en Redoble por Rancas}

Para Galtung (1969), la violencia estructural está integrada en la estructura y se manifiesta como una desigualdad de poder (p. 171). Por lo tanto, la violencia directa requiere tanto de la violencia cultural como de la estructural. Asimismo, este autor, dentro de la categoría de la violencia estructural, clasifica la desigualdad social. Ahora bien, una de las circunstancias descritas en $\mathrm{RpR}$, que configuran implacablemente esta desigualdad, es la pobreza. Esta aparece como una condición que resiste a toda lucha y actúa permanentemente en la vida social de los personajes campesinos. Esta violencia invisible tiene un impacto significativo en la calidad de vida de estos, debido a la impotencia que afecta su integridad física y moral, como se expresa en el capítulo 14, cuando las ovejas comenzaron a fallecer por culpa del cerco:

Las ovejas siguieron muriendo. Los viejos se desesperaron. Ni en los recovecos de la memoria encontraban esos recuerdos.

-Nos llegó la hora -decía Valentín Robles-. Ya falta poco para que clausuren el pueblo. Ahora sí, ahora nos comeremos entre humanos. El padre se comerá al hijo; el hijo se comerá a la madre.

-Si pudiéramos, iríamos a otros pueblos a suplicar, pero no se puede. Encima de la pampa solo hay aire.

-Mejor que se lleven todo. Ojalá que el muro entre al pueblo. Ojalá muramos todos. Muertos no pediremos ni agua. (Scorza, 1983, p. 94)

Como podemos constatar, el despliegue de este tipo de violencia se asegura a través de sistemas que la legitiman, sean legales o no. Nos referimos a que al poder político y económico no le interesa solucionar las causas que generan pobreza y se centra más en su castigo; como vemos en el caso de los peones que decidieron unirse en un sindicato y fueron engañados y envenenados por el patrón, don Migdonio (capítulo 15). Pero, como expresa el narrador, no se hizo justicia: "El dictamen del doctor Montenegro fue categórico: los peones habían sido segados por el primer infarto colectivo de la historia de la medicina" (Scorza, 1983, p. 126). Por lo tanto, constatamos que subyace un sistema selectivo que controla y subyuga a ciertos sectores, puesto que, para algunos grupos, se justifica su criminalización, al mismo tiempo que se les ofrece a otros oportunidades y beneficios sociales.

De este modo, la violencia se intensifica y se alienta por la hostilidad, la discriminación y las restricciones a la participación en la vida cultural o económica. De esta forma, se agrava la situación de desigualdad de la población, empujándola a conductas violentas o delictivas como única forma de acceder a sus derechos. Cabe agregar, además, que una vez que los grupos excluidos han optado por la violencia para obtener lo que el Estado les ha negado, la violencia se convierte paulatinamente en una forma de conseguir reconocimiento y, a la vez, es un medio para justificar el castigo por parte del Estado. 
Dentro de este marco, retomamos la categorización de Galtung (1990) respecto de los actores involucrados en la violencia estructural ${ }^{7}$. Como resultado, observamos la existencia de un conflicto entre dos grupos: el poder político y económico versus el campesino de Rancas. El primero, topdogs, aparece tipificado en cuanto a su posición en el poder y es él quien se beneficia de esta situación de desigualdad; mientras que el segundo, underdogs, es caracterizado en términos de clase social, etnia y situación de desventaja social. Dicho de este modo, comprobamos que estas estructuras de estratificación social a menudo se resuelven sistemáticamente a favor de los segundos en detrimento de los primeros.

Desde este ángulo, ya no hablamos de individuos, sino de un grupo privilegiado que posee ese poder de decisión, que bien podría ser el Estado o el poder económico. Estos, con base en leyes, otorgan ventajas a ciertos grupos en detrimento de otros. Por ejemplo, la entrada de la empresa Cerro de Pasco Corporation, que beneficia económicamente a sus miembros, pero que repercute en el acceso de la población a los servicios básicos, genera un conflicto que la confronta directamente con la población. El Estado es el que define la situación optando primero por ignorar las denuncias de las víctimas para luego intervenir con la fuerza para silenciar las protestas. De esta forma, se mantiene esta situación de disparidad en la distribución de beneficios.

Asimismo, la violencia llevada a cabo en esta obra es también una violencia histórica que en su despliegue devuelve el pasado al presente. Es decir, la intersección de dos momentos diferentes de la historia en el capítulo 32 (Scorza, 1983, p. 230) confiere una infalible alegoría a la violencia, como mítica e intrínseca al sistema del poder. En este sentido, observamos que aparecen otras dos concepciones de la violencia -en la terminología de Benjamin citada en Camargo (2015) —: una que fundamenta la ley y otra que la preserva. Así, el intercalar las dos anécdotas - el momento de la llegada de la Guardia Civil con los hombres de la Cerro de Pasco Corporation y el acontecimiento de la batalla de Junín - tiene por objetivo la representación de la violencia como medio para el establecimiento de un nuevo derecho. Es decir, el sistema del poder establece la violencia como una alternativa para mantenerse. Y, por otro lado, funda un nuevo derecho cuando otorga a la Cerro de Pasco Corporation las herramientas legales para incrementar su propiedad privada en tierras de poblaciones indígenas como es el caso de Rancas.

Del mismo modo, la violencia interviene por parte de los campesinos como una forma de resistencia al desalojo ilegítimo y está fundamentada en el derecho de reclamar y

7 En el artículo "Cultural Violence", publicado en 1990, Galtung menciona que en la violencia invisible es difícil distinguir a los actores; sin embargo, los clasifica como underdogs y topdogs; los primeros son todos actores que se encuentran socialmente en desventaja en comparación con los demás; los segundos son los que se benefician de una coyuntura de asimetría de poder. 
revindicar sus propiedades. Con la lucha fundada en violencia, buscan exigir una modificación en el derecho establecido por la ley. En consecuencia, se la utiliza como medio para reclamar abusos. Como respuesta a ello, el sistema del poder interviene con la fuerza permanente y necesaria para preservar su derecho amenazado, lo que explica el carácter cíclico del desenlace de todas las novelas de La guerra silenciosa de la que RpR forma parte.

Todo lo dicho hasta aquí parece confirmar nuestras consideraciones anteriores de que la novela expone dos tipos de violencia que expresan y muestran la crudeza de las situaciones representadas y la periferia y marginalidad de los personajes. Asimismo, cuando se pone en escena la relación violenta del individuo con su entorno, inmediatamente emergen problemas sociales, culturales y económicos que imposibilitan al violentado modificar su entorno. En todo caso, la dinámica entre historia y memoria resulta omnipresente en el espacio textual de RpR. Por esta razón, consideramos que la citada novela posee el papel de mediar y negociar los pasados que propone contar y desde luego se ofrece como una instancia para reparar simbólicamente los efectos de la violencia política.

\section{JUSTICIA POÉTICA Y MEMORIA RESTAURATIVA ${ }^{8}$ EN REDOBLE POR RANCAS}

En las ciencias humanas, el debate sobre la memoria colectiva encuentra su base empírica en el periodo de transición hacia la democracia en sociedades que en el pasado sufrieron violaciones sistemáticas de los derechos humanos por regímenes autoritarios y represivos, por ejemplo, de la Alemania nazi y del régimen totalitario de Franco en España (Rivera Revelo, 2020, p. 33).

No obstante, cabe señalar que si el estudio de la memoria en el marco mundial se llevó a cabo después de la Segunda Guerra Mundial, en América Latina no empezó a consolidarse sino hasta las dos últimas décadas del siglo pasado. Concretamente, nos referimos a la época histórica que corresponde al fin de la dictadura en el continente americano, y la transición hacia la democracia llamada también la tercera ola democrática (Huntington, 1994). Esta última constituye el principal motor del cambio, que impulsa a que la memoria ocupe el centro de las discusiones tanto académicas como políticas. Otro rasgo de la mencionada transición es la instauración de la Comisión de la Verdad y

8 El concepto de memoria restaurativa fue propuesto por la estudiosa Lucero de Vivanco en su ensayo "Tres veces muertos: narrativas para la justicia y la reparación de la violencia simbólica en el Perú" (2018). Como lo explica, "lo que sostiene el adjetivo restaurativo, que califica el concepto de memoria, está en directa relación con el desarrollo reciente de las teorías y prácticas respecto de la llamada justicia restaurativa" (p. 135). En este sentido, la autora ratifica que la narrativa de memoria que representa la falta de justicia transicional puede implementarse como una instancia para la reparación de la violencia subjetiva. 
Reconciliación, que, desde luego, contribuyó a la consolidación de la investigación sobre la memoria en América Latina?.

En el contexto peruano, algunos estudios críticos y académicos sobre la memoria histórica y la memoria colectiva han cuestionado la omisión de la historia de violencia en tiempos de la movilización por la tierra, precisamente desde la década de 1960. Al respecto, sostenemos que, en relación con la lucha campesina del periodo mencionado, no solo hay un déficit de memoria por la ausencia de información sobre las realidades relacionadas con lo ocurrido, sino también un déficit ético y político que impide construir verdaderos vínculos con un pasado marcado por el trauma y la violencia, y que todavía afecta la actualidad peruana.

En el mismo contexto, si volvemos la mirada a los sucesos relatados por Scorza en la novela del corpus, observamos que el propio autor aporta una reflexión sobre el problema de la representación del pasado en la historia peruana. Dicho de otro modo, Scorza manifiesta, por medio de la ficción literaria, una sutil crítica a los historiadores peruanos, en cuanto a que retrataron las sublevaciones de los Andes centrales como básicamente causadas por problemas agrarios. Por esta razón, la simbología del silencio ocupa un lugar bastante elocuente en el ciclo narrativo scorziano, empezando por nombrarlo como "una guerra silenciosa".

Así podemos observar que en RpR el silencio no se evoca como un vacío, sino que está "poblado de signos" (Paz, 1972, p. 6), ya que el propio autor le confiere diversas dimensiones significativas, vinculadas a la alineación del pueblo indígena. Este último aparece evocado desde la impotencia y el abandono; como dice el narrador: "Rancas es el culo del mundo" (Scorza, 1983, p. 28).

En paralelo, subrayamos que las reiteradas masacres ante las injusticias que padece Rancas establecen la forma más esclarecedora de sofocar y silenciar al pueblo. Por tanto, el silencio simboliza una falta de voluntad de entendimiento de su causa y, por ello, el autor suele calificar a la lucha de los campesinos como "solitaria" (así lo menciona en el prólogo de RpR).

Del mismo modo, el autor, por medio del procedimiento de la ironía que impregna toda la narración de profundos significados políticos, retrata la indiferencia de la sociedad frente a la pugna de los pueblos indígenas y el silenciamiento de lo sucedido. Para el caso, citamos la evocación irónica de afecciones y padecimientos, tales como el "daltonismo" y la propagación de un virus que representan el miedo y la indiferencia en

9 Otra razón por la que la memoria ha tomado gran importancia en la sociedad latinoamericana está relacionada con el constante miedo a olvidar; en muchos casos, esta dicotomía establecida entre la memoria y el olvido se convertirá en el motor impulsor de las iniciativas de memoria que acabamos de mencionar. 
que se ubica gran parte de la población frente a la tiranía y al dolor, tal como se evidencia en estos fragmentos:

Un desconocido virus infectó los ojos de los habitantes. Aparentemente, las víctimas gozaban de la integridad de su visión, pero un novedoso daltonismo les escamoteaba algunos objetos. Un enfermo capaz de señalar, por ejemplo, las manchas de una oveja a un kilómetro, era incapaz de distinguir un cerco situado a cien metros. (Scorza, 1983, p. 193)

$[\ldots]$

Oficiosos amigos informaron a los señores concejales, sobre todo a los comerciantes, que estaban a una pestaña de ganarse un lugar en la lista negra de "La Compañía"; los atacó otra enfermedad: paludismo de dientes. (Scorza, 1983, p. 195)

En todo caso, la simbología que adquiere el "silencio" confiere las siguientes denotaciones: por un lado, invoca el drama colectivo de las víctimas y, por otro, presenta una denuncia a la omisión y la falta de compromiso de la historia oficial en relación con las sucesivas y genuinas injusticias cometidas contra los pueblos indígenas. De este modo, RpR forma parte del verdadero campo de batalla y del despojo de la historia hacia lo simbólico y lo estético. Asimismo, asume un papel catártico que opera desde los márgenes de la historia, sondeando sus rincones acallados e instalando la duda en el lugar de las "verdades". Visto así, Scorza suscribe su uso de la historia y del pasado en el arte literario como una persistente apuesta simbólica.

Siguiendo estas consideraciones, podemos afirmar que todo el hilo narrativo de $\mathrm{RpR}$ se transforma en una lucha literaria para la reconstrucción de la memoria colectiva y para una justicia restaurativa a favor de las víctimas del pueblo de Rancas, doblemente masacradas: una injusticia física y otra como violencia simbólica (el olvido y la invisibilidad). Al respecto, nos resulta más plausible el estudio de Vivanco (2018) sobre la narrativa como instancia de reparación, en el cual recupera el mecanismo jurídico de la justicia restaurativa y lo aplica al análisis de la narrativa de denuncia, derivada del conflicto armado entre el Estado peruano y Sendero Luminoso. De acuerdo con la autora, la renuncia explícita a la justicia o a la reparación "oficial" ha posibilitado, en la literatura peruana, la emergencia de una narrativa que se ofrece como una instancia de "simbolización" y "reparación" de esta violencia subjetiva. Son narrativas básicamente circunscritas a emociones y afectos. De este modo, como expresa Vivanco (2018), la literatura opera como un "potencial" encuentro entre la víctima y la sociedad "ofensora"; y, en última instancia, permite el acto de justicia ${ }^{10}$ con su respectiva reparación. Y agrega que "las memorias restaurativas" se ofrecen, entonces, no solo como instancias para la elaboración de la memoria de violencias cometidas, sino también para modificar este

10 El énfasis es nuestro. 
"torcido curso de las relaciones sociales en el Perú" que ha condenado a innumerables peruanos a su triple muerte (pp. 153-136).

Ahora bien, si consideramos que RpR visibiliza el sufrimiento de los sectores más vulnerables de la sociedad altoandina, el mencionado planteamiento de Vivanco (2018) nos resulta más pertinente para enfocar el análisis del corpus de trabajo como narrativa de memoria restaurativa que se encamina hacia la reconstrucción de la memoria colectiva como acto de justicia simbólica.

Para empezar, conviene enfatizar que RpR es una narrativa que pone en primer plano la memoria del subalterno, sin mediación de un discurso hegemónico. Así se establece una dialéctica constante entre el silencio y la posibilidad de poner en palabras lo traumático. A nivel textual, se acortan las mediaciones entre derechos humanos y escritura literaria, pues el texto narrativo de RpR funciona como portador de una realidad obvia, donde los personajes constituyen sujetos colectivos capaces de generar emociones y empatía que prácticamente, a nuestro juicio, consiguen ampliar las posibilidades de acceso al derecho de visibilidad.

Entonces, podemos afirmar que la narrativa scorziana es esencialmente de denuncia social. De acuerdo con Guaraglia Pozzo (2018), el "poder potestativo" de la saga La guerra silenciosa busca "investir a los sujetos agraviados con la legitimidad que les garantiza el deber de reclamar el derecho a tener derechos" (p. 63). Por eso, tanto RpR como las otras novelas que componen el ciclo se vinculan por una modalidad argumentativa idéntica, a saber: el discurso persuasivo aparece como mecanismo de denuncia que manifiesta el sufrimiento de las comunidades y la situación de violaciones de los derechos humanos presentes por las relaciones asimétricas de poder. En ese sentido, las injusticias son argumentadas por medio de datos reales y otros ficticios con el fin de convencer a la audiencia (el lector) y encontrar por medio de la empatía la aprobación de la legitimidad de la lucha comunera. De esta manera, el autor propone nuevos sujetos que resisten a la penuria y luchan por la dignidad y la inclusión.

Partiendo de estos supuestos podemos afirmar que el propósito ético de la ficción en RpR es llevar la experiencia del dolor de los sujetos silenciados al espacio público. Y, por supuesto, asume la posición defensora de los derechos y una herramienta de justicia restaurativa. Se trata, entonces, de resarcir el dolor mediante el acceso a la verdad. Por tanto, la reparación, en este caso, no es física, sino simbólica ante la imposibilidad de otorgar una legitimidad oficial a la lucha comunal de Cerro de Pasco en los años sesenta.

Como se puede inferir, el testimonio ficcionalizado en la citada novela se establece como una voz viva, que preserva la memoria ante la violencia, por un lado; y, por otro, se convierte en "un rito funerario simbólico" (Vivanco, 2018, p. 128), donde los muertos y las víctimas de la masacre adquieren voz en la memoria de la comunidad, e incluso en 
la memoria universal. Del mismo modo, este testimonio, que se encamina hacia la reparación, se instituye en la obra como un acto judicial" ${ }^{11}$. Evidentemente, no busca formar parte del expediente de la fiscalía en un juicio, sino que está destinado a preparar el terreno para que el tribunal de la historia y del colectivo lector emitan su juicio sobre los hechos documentados. No obstante, el mencionado acto judicial del testimonio literario presupone no solo decir la verdad, sino también probar esa verdad por medio de su dispositivo narrativo, su polifonía, la complejidad de sus personajes, su trama y su capacidad de transformarse en un espacio donde coexisten diferentes tiempos históricos que posibilitan echar un vistazo al pozo del pasado. Aun así, Scorza, al evocar la memoria, no pretende elaborar un simple trabajo de revisión del pasado, sino que propone un modo de justicia que evita que las víctimas de estos crímenes mueran dos veces: una en la realidad histórica y otra en el olvido de la sociedad.

Atendiendo a estas consideraciones, comprobamos que la poética literaria de RpR posee una vocación jurisdiccional, en la medida que ofrece una perspectiva crítica sobre la justicia a través de sus dispositivos enunciativos, que nos permiten acceder al punto de vista de los demás y, al mismo tiempo, nos revelan una profunda desconfianza frente a la institución judicial o sus representantes para conseguir justicia. Al respecto, citamos en particular el prólogo "La noticia" con que comienza RpR, donde el narrador expresa "ciertos hechos y su ubicación cronológica, ciertos nombres [que] han sido modificados para proteger a los justos de la justicia" (Scorza, 1983, p. 9). Como se puede observar, se asocian dos lexemas (justos, justicia) que pertenecen al mismo campo semántico, pero que aparecen en el texto como opuestos. Este contraste tiene, efectivamente, la peculiaridad de articular explícitamente la relación entre justicia civil y "justicia poética”, colocando así dos lecturas opuestas. Nos referimos en este caso a la de los hombres de la ley y la del escritor, como el literato, que busca ofrecer una visión más "rica" y "completa" que haga justicia a la vida humana (Nussbaum, 1997, p. 77). En otras palabras, la narrativa de RpR proporciona al lector una forma de posicionarse, reflexionar y sobre todo sentir empatía, que a nuestro juicio propicia ampliar posibilidades de acceso al derecho de visibilidad y, por supuesto, a tener voz en la historia. Así, la citada novela, por medio del acceso a la verdad, no se limita a ofrecerse como una instancia para la reparación, sino que también funciona como una modalidad de justicia que sustituye a otra que ha permanecido callada o equivocada.

A este respecto, retomamos el supuesto de Nussbaum (1997) que plantea a la literatura como una herramienta que puede mejorar el funcionamiento de la ley $y$, más ampliamente, de la vida pública. Para extender la explicación, la autora propone el enfoque de la imaginación y la empatía como herramientas que apoyan al novelista

11 El énfasis es nuestro. 
para entrar en la vida de los "otros" distantes y aprehender su individualidad (pp. 25-35). Desde este ángulo, consideramos que RpR se sirve de la imaginación para aprehender y representar "seres plenamente humanos", dando acceso a otros mundos subjetivos; y al hacerlo permite que se haga justicia, tanto literal como metafóricamente. De esta manera, se confiere al "narrador" la capacidad de aportar la literatura a la vida pública y más concretamente a la institución judicial, en cuanto genera un debate público.

Como se puede deducir, la literatura es concebida por Scorza del mismo modo en que la concibe Ricœur (1990), como "un vasto laboratorio en el que son ensayadas estimaciones, evaluaciones, juicios de aprobación y de condenación por los que la misma narratividad sirve de propedéutica a la ética" (p. 139).

Lo dicho hasta aquí confirma que RpR posee "el potencial" de poner el dolor de sujetos no-históricos en la escena pública, como lo plantea Nussbaum (1997) cuando se refiere al poder de la literatura y su potencial de hacer "contribuciones al derecho en particular y al razonamiento público en general" (p. 17). Al respecto, llama la atención cómo la narrativa de RpR va a tener eco más tarde en el ambiente sociopolítico del Perú. Aquí mencionamos el caso del héroe Héctor Chacón, el Nictálope, que, como muchos de los héroes de la pentalogía, tiene una referencia real. Era un líder campesino que fue capturado y encarcelado en la selva, con una sentencia de veinte años de prisión. Sin embrago, después de la publicación RpR y el eco nacional e internacional que tuvo, el general Velasco Alvarado ordenó la liberación del Nictálope y fue el mismo Scorza quien vino a darle al líder esta grata noticia. Este acontecimiento fue publicado en la revista bonaerense Crisis, donde dice:

Héctor Chacón, el Nictálope, escribe una carta a la revista Caretas confirmando que se encuentra cumpliendo desde hace once una condena de veinticinco años de cárcel por haber ejecutado a un traidor a la comunidad de Yanacocha. La carta provoca intensa emoción. Un grupo de escritores peruanos constituye un comité pro-liberación del Nictálope. Scorza viaja al Perú para solicitar la libertad de Héctor Chacón. El presidente del Perú, general Velasco Alvarado, anuncia que Héctor Chacón, "símbolo del sufrimiento de los comuneros del Perú", será liberado el 28 de julio [de 1971], sesquicentenario de la Independencia del Perú. (Como se citó en González Soto, 1996, p. 162)

Más aún, en 1975, cuando Velasco Alvarado fue destituido por el general Francisco Morales Bermúdez, se dio la continuidad de los proyectos de reforma agraria en el Perú, anunciada exactamente en Rancas, lo que explica, en palabras de Scorza, que la literatura cumple su función gracias a la novela y que "la rebelión de Rancas salió del anonimato a la evidencia" (como se citó en González Soto, 1996, p. 162).

De hecho, la ficción literaria de RpR reflexiona éticamente sobre la relación que mantiene la literatura con el mundo, y mediante la cual se vehiculiza el dolor inmerecido 
y se hace de él una exigencia de reparación. El propio Scorza lo ha señalado en una conversación con Manuel Osorio:

Para mí, los libros son un recurso de apelación. Cuando en América Latina se pierden todas las instancias - por ejemplo, cuando en un combate humano un Gobierno masacra a todo un pueblo-, entonces queda la posibilidad de escribir un libro, y el libro reabre el debate. La rebelión de los comuneros de Cerro de Pasco - una de las miles de rebeliones que recorren clandestinamente nuestra historia continental- hubiera desaparecido en el olvido. (Como se citó en González Soto, 1996, p. 162)

En síntesis, comprobamos que RpR, por medio de la ficción, busca representar el dolor individual y colectivo, revelar las caras ocultas de la historia y castigar, con los medios que le son propios, el mal. De este modo, la obra pone en escena cuestiones silenciadas en la historia e interpreta los archivos. No obstante, el autor evoca la subalternidad sin mediación del discurso hegemónico ni de los mecanismos y procesos institucionales de la justicia transitoria. En otras palabras, la justicia propuesta por el autor radica en que esta literatura aúna justicia histórica y justicia transitoria, o más bien trasciende ambas dentro de lo poético. No obstante, representar el sufrimiento no busca compensación o justicia temporal, sino que, en cierto sentido, por medio de la ficción, la mencionada novela perpetúa, precisamente, lo transicional en la justicia restaurativa. También rechaza cualquier asimilación entre dolor y conveniencia material (dolor contra el dinero, dolor contra el perdón). Como observamos, la ficción scorziana registra la imposibilidad de tal intercambio, porque el dolor es traumático y remediarlo requiere incorporar la voz de la víctima en la historia y, desde luego, reconocer su derecho. En consecuencia, evocar las injusticias, dar voz a los no-históricos y revelar el dolor, en $\mathrm{RpR}$, aparecen, ante todo, bajo la forma de una memoria reparatoria que busca poner el dolor de las víctimas en la escena pública y desde luego esta misma reparación simbólica configura un acto judicial que, aunque sea ficticio, resulta ser ideal para superar el trauma y para que las víctimas puedan -aunque no definitivamente-cerrar sus duelos.

\section{CONCLUSIONES}

El estudio tanto general como detallado de RpR nos ha permitido, por un lado, reflexionar sobre la escritura de la historia y la relación que guarda con la novela; y, por otro, plantear el arte literario como el único territorio potente en actuar con libertad expresiva y estética para intervenir en lineamientos sociopolíticos. Para ello, hemos iniciado nuestra indagación empezando, primero, por considerar el texto narrativo de RpR como testigo de la realidad, ya que hechos reales como las revueltas de los comuneros de Pasco entre 1950 y 1962 van a ser su referencia histórica y el hilo de toda la narración. Por eso, hemos subrayado que la memoria, el testimonio y otros materiales se entrelazan en 
la citada novela, capturando con lupa una parte de la realidad individual y colectiva de quienes han sido eternamente excluidos.

Por otro lado, mediante el análisis de la construcción discursiva de la violencia política en la novela objeto de nuestro estudio, hemos concluido que la violencia se configura como un proceso complejo que implica no solo una manifestación para infligir daños a otros, sino que, para llegar a esto, hay una serie de mecanismos insertos en las prácticas sociales, entre las cuales destacamos la humillación, por medio de la cual el conflicto es implícito en las relaciones sociales. Asimismo, hemos concluido que los campesinos empujados a la autodefensa se posicionan en la acción, recurriendo a la lucha y protestando contra el ataque a su propiedad. Entonces, el pueblo se encuentra frente al abusador y manifiesta así su derecho a la insurrección, a través de la revuelta en nombre de la resistencia a la opresión. Por lo tanto, la inscripción de las huellas corporales en el texto desafía la sensibilidad del lector para que pueda imaginar el grado de sufrimiento que siente la víctima. De este modo, el cuerpo, en un escenario de violencia directa, se convierte en un símbolo que se forja socialmente en una nueva red de sentido. Por tanto, confirmamos que la novela RpR da cuenta del tránsito de la violencia visible y directa a otras formas de violencias provocadas por las injusticias y la polarización de las clases sociales.

Por otro lado, hemos comprobado que Scorza, además de contar una historia, sugiere estéticamente una serie de consideraciones éticas sobre el conflicto y los procesos de (re)configuración de la memoria y el olvido social. A partir de este planteamiento, hemos confirmado nuestra premisa de que la poética literaria de RpR posee una vocación reparatoria en la medida en que visibiliza las historias no contadas de personas "no históricas" y, por ende, formula, por medio de la empatía, una reparación simbólica del daño. No obstante, hemos considerado que el texto narrativo del corpus no se limita tan solo a ofrecerse como una instancia para la reparación, sino que también funciona como una modalidad de justicia que sustituye a otra que ha permanecido callada o equivocada. En definitiva, RpR se instaura como una narrativa de memoria que transforma la literatura en una herramienta de denuncia contra las prácticas inhumanas y contra la invisibilidad del dolor humano.

\section{REFERENCIAS}

Arendt, H. (2005). Sobre la violencia. Alianza Editorial.

Camargo, R. (2015). Para una crítica de la violencia (divina): notas sobre una (re) inscripción política. Polis (Santiago), 14(42), 305-323. doi: 10.4067/S071865682015000300014 
Cantis Carlino, D. (2000). Transformaciones en la cultura, violencia cotidiana y psicoanálisis. Psicoanálisis APdeBA, 22(2), 333-344. http://biblioapdeba.no-ip. org/pgmedia/EDocs/2000-revista2-cantis

Chati, G. (2015). Historia y memoria campesina: silencios y representaciones sobre la lucha por la tierra y la represión en Ongoy. Anthropologica, 33(34), 35-62. http://www.scielo.org.pe/scielo.php?script=sci_arttext\&pid=S0254$92122015000100003 \& \operatorname{lng}=e s \&$ tlng=es

Cortez, E. (14 de agosto del 2020). Ficción y testimonio en la narrativa peruana de la violencia política [15. ${ }^{a}$ charla magistral]. Programa de Literatura Peruana, organizado por la Biblioteca Nacional del Perú. https://www.facebook.com/ BibliotecaNacionalPeru/posts/10158703766738234

Foucault, M. (2006). Seguridad, territorio, población. Curso en el Collège de France (19771978) (H. Pons, Trad.). Fondo de Cultura Económica.

Galtung, J. (1969). Violence, Peace, and Peace Research. Journal of Peace Research, 6(3), 167-191. http://www2.kobe-u.ac.jp/ alexroni/IPD\%202015\%20readings/ IPD\%202015_7/Galtung_Violence,\%20Peace,\%20and\%20Peace\%20Research. pdf

Galtung, J. (1990). Cultural Violence. Journal of Peace Research, 27(3), 291-305. https:// www.galtung-institut.de/wp-content/uploads/2015/12/Cultural-ViolenceGaltung.pdf

Galtung, J. (1998). Tras la violencia, 3R: reconstrucción, reconciliación, resolución. Afrontando los efectos visibles e invisibles de la guerra y la violencia (T. Toda, Trad.). Bakeaz; Gernika Gogoratuz.

González Soto, J. (1996). El tiempo del mito en Redoble por Rancas, de Manuel Scorza. Boletín Americanista, 46, 82-161.https://raco.cat/index.php/BoletinAmericanista/ article/view/98649

Guaraglia Pozzo, M. (2018). Morir de pie. Una aproximación a los derechos humanos a partir de dos novelas latinoamericanas. Valenciana, 22, 53-79. https://www. redalyc.org/articulo.oa?id=360357138003

Huamanchumo, 0. (2013). Protesta social en el discurso simbólico de La guerra silenciosa de Manuel Scorza. En E. Huárag (Ed.), Violencia social y política en la narrativa peruana (pp. 249-272). Pontificia Universidad Católica del Perú, Instituto Riva Agüero. http://es.ofeliahuamanchumo.com/wp-content/uploads/ sites/5/2017/02/2_Huamanchumo_2014_Protesta-social-Manuel-Scorza.pdf

Huntington, S. (1994). La tercera ola: la democratización a finales del siglo. Paidós. 
Nussbaum, M. C. (1997). Justicia poética: la imaginación literaria y la vida pública (C. Gardini, Trad.). Andrés Bello.

Paz, 0. (1972). El arco y la lira (3. a ed.). Fondo de Cultura Económica.

Ricœur, P. (1990). Soi-même comme un autre (A. Neira, Trad.). Éditions du Seuil.

Rivera Revelo, L. (2020). Memoria, reparación simbólica y arte: la memoria como parte de la verdad. Foro, Revista de Derecho, 33, 30-65. doi: 10.32719/26312484.2020.33.3

Schwartz, M. E. (2009). París no siempre fue una fiesta...: la política transnacional de la cultura en "La danza inmóvil" de Manuel Scorza. Biblioteca Virtual Miguel de Cervantes. http://www.cervantesvirtual.com/obra/pars-no-siempre-fue-una-fiesta-lapoltica-transnacional-de-la-cultura-en-la-danza-inmvil-de-manuel-scorza-0/

Scorza, M. (1983). Redoble por Rancas. Plaza y Janés.

Sofsky, W. (2006). Tratado sobre la violencia (J. Chamorro Mielke, Trad.). Abada Editores.

Vivanco, L. de. (2018). Tres veces muertos: narrativas para la justicia y la reparación de la violencia simbólica en el Perú. Revista Chilena de Literatura, 97, 127-152. doi: $10.4067 /$ S0718-22952018000100127 